\title{
Evaluation of Regional Climate Simulations of the 1998 and 1999 East Asian Summer Monsoon using the GAME/HUBEX Observational Data
}

\author{
L. Ruby LEUNG \\ Pacific Northwest National Laboratory, Richland, Washington, USA \\ Shiyuan ZHONG \\ Department of Geosciences, University of Houston, Houston, Texas, USA \\ Yun QIAN \\ Pacific Northwest National Laboratory, Richland, Washington, USA \\ and \\ Yiming LIU \\ National Climate Center, China Meteorological Administration, Beijing, China
}

(Manuscript received 7 July 2003, in final form 11 June 2004)

\begin{abstract}
A regional climate model based on the Penn State/NCAR Mesoscale Model (MM5) was used to simulate the 1998 and 1999 East Asian summer monsoon conditions. Simulations were performed for 1 April-31 August of each year, with initial and lateral boundary conditions provided by the ECMWF analysis. Observations from the 1998 and 1999 GAME/HUBEX experiments were used to evaluate the regional climate simulations. Based on observations, large differences can be found between the 1998 and 1999 meteorological conditions and surface energy budgets at the Shouxian station during the IOPs, with much higher rain intensity but only slightly higher rain frequency in 1998 than 1999. For 1998, although the regional climate model was able to reproduce the general spatial distribution of monthly mean rainfall quite well during the summer monsoon season, large discrepancies can be found in comparing the observed and simulated surface climate and energy fluxes in the HUBEX region. By using Four Dimensional Data Assimilation (FDDA) technique, which constrains the simulated large-scale circulation with observations from 21 soundings in the HUBEX $\alpha$-scale region, both the root mean square error and mean bias in rainfall were greatly reduced. The improvements in simulating rainfall were related to both reduction in errors of precipitation amount and timing. In the control simulation, a mean bias of $-63 \mathrm{~W} / \mathrm{m}^{2}(-36 \%)$ was found in the simulated surface net radiation at Shouxian, which suggest large errors in simulating clouds in the region. With FDDA, the bias was significantly reduced to $-23 \mathrm{~W} / \mathrm{m}^{2}(-13 \%)$, with corresponding reduction of bias in the latent heat flux. This suggests that at
\end{abstract}

Corresponding author: L. Ruby Leung, Pacific Northwest National Laboratory, Richland, Washington, USA.

(C) 2004, Meteorological Society of Japan 
least part of the model bias in simulating net radiation is related to errors in simulating the large-scale circulation, which can affect cloud amount and vertical distribution.

Comparing the 1998 and 1999 simulations, both without FDDA, smaller biases were found in the surface fluxes during 1999. Percentage biases in the net radiation and latent heat flux were $-18 \%$ and $-33 \%$ in 1999 and $-36 \%$ and $-50 \%$ in 1998 respectively. Based on observations, large differences in the net surface radiation, and small differences in cloud fraction between the two years suggest that cloud optical depth and/or vertical distribution were very different, with more cloudy conditions observed during 1999. Although the 1999 simulations were sensitive to the cumulus convective parameterizations (Grell scheme versus Kain-Fritsch scheme) as shown by the sensitivity experiments, the large differences in simulation skill between the 1998 and 1999 cases, regardless of the convection schemes used, suggest possible dependence of model errors on cloud properties that deserve further investigations.

\section{Introduction}

The goals of the GEWEX Asian Monsoon Experiment (GEWEX/GAME) project are to understand the role of the Asian monsoon in the global climate system, and develop methods for long-range forecasting of the monsoon and regional hydrological cycle. As part of the GEWEX/GAME project, the Huaihe Basin Experiment (HUBEX) focuses on the study of cloud and precipitation systems, and landatmosphere interactions in an area strongly affected by the Meiyu monsoon frontal system (GAME/HUBEX Office 1997). During the summer of 1998 and 1999, a large number of observation systems were used to obtain conventional surface measurements, upper-air soundings, and hydrologic measurements during two Intensive Observation Periods (IOPs). In addition, surface energy and moisture fluxes were measured at the Shouxian Station (Fig. 1) within the Huaihe River basin to investigate land surface processes (GAME-ISP 1998). This study makes use of the HUBEX data to evaluate regional climate simulations of the 1998 and 1999 summer monsoon in East Asia.

The East Asian summer monsoon (EASM) exerts a dominant influence on rainfall in China, and often leads to concurrent flood and drought conditions in different parts of the country. Unlike the South Asian summer monsoon (SASM), which is characterized by annual reversal of the low level zonal wind, caused by the north-south thermal contrast between the Indian Ocean and the Asian land mass and the Tibetan Plateau, the EASM is a subtropical phenomenon characterized by reversal of meridional wind caused by the east-west thermal contrast between the Asian continent and the Pacific Ocean. Furthermore, in contrast to the
SASM, which is governed by only one moisture source from the low-level southwesterly flow associated with the Somali Jet, three branches of airflows affect the EASM precipitation in China: the Indian summer monsoon flow; the cross-equatorial flow over Southeast Asia and the South China Sea; and the southeast monsoon flow from the southern flank of the Subtropical High over the western North Pacific (Ding 1994).

The EASM is characterized by prominent spatial and temporal discontinuity of rainfall that challenges climate modeling. There are multiple monsoon rainfall onsets over East Asia as the rainband makes rapid transitions

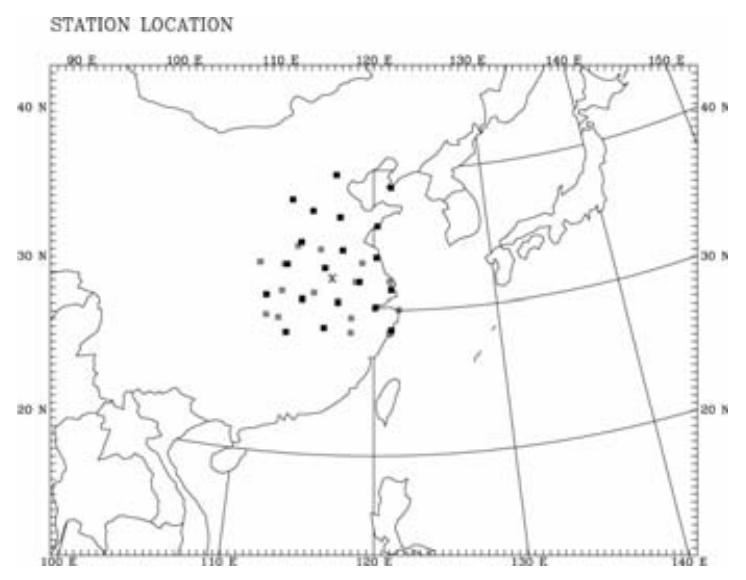

Fig. 1. The regional climate model domain and locations of the 21 sounding stations (black), 17 surface meteorological stations (grey), and the Shouxian flux station $(\mathrm{x})$. The Shouxian station is also the location of a surface meteorological station and a sounding station. 
between three stationary positions over southern, central, and northeastern China in association with the pre-monsoon rain, Meiyu front, and the Polar front (Lau et al. 1988). Because of the convective nature of precipitation, strong cloud-radiation and land-atmosphere feedbacks, and heterogeneous surface forcings, climate models often fail to realistically capture the location and intensity of the rainband. Some studies suggested that by resolving climate processes and climate forcings at the appropriate spatial scales, regional climate models (RCMs) are useful tools for studying the hydrological cycle of the EASM (e.g., Leung et al. 1999; Wang et al. 2003). Preliminary investigations have been performed in recent years to use a model nesting approach whereby regional scale seasonal climate predictions are produced with RCMs driven by ensemble General Circulation Model (GCM) seasonal climate forecasts (e.g., Ding et al. 2003), with the goal to improve seasonal prediction skill. Although limited successes have been reported demonstrating the ability of RCMs to capture important regional scale climate features of the EASM, their applications to the monsoon region deserve additional investigations.

In an intercomparison experiment of regional climate simulations of the 1991 flood in China, Leung et al. (1999) showed that regional climate simulations of the EASM are particularly sensitive to the parameterizations of clouds, cloud-radiation feedbacks, and land surface processes. In the EASM region, where spatially extensive and optically thick clouds are observed frequently (Rajeevan and Srinivasan 2000), model bias in simulating the cloud amount, optical depth, and vertical distribution can greatly amplify errors in the cloud radiative forcing and atmospheric and surface heating that induce errors in the large-scale circulation and hydrological cycle through various feedback mechanisms. The treatments of land surface processes are also important because they govern the partition of surface energy and water among the various components that control important feedbacks to the atmosphere.

Limited by available data, previous efforts on understanding model sensitivity and evaluating regional climate simulations were mainly performed using global analyses of large-scale circulation and a few observed variables, such as surface temperature, precipitation, and very limited components of the energy and water budgets. Taking advantage of the GAME/ HUBEX field experiments, this study aims at evaluating regional climate simulations of the EASM, particularly the surface energy and water budgets, and examining the sensitivity of simulations to a number of modeling factors. Section 2 describes the HUBEX data that are used in this study. Section 3 describes the regional climate model and numerical experiments, and Section 4 discusses the results of the 1998 and 1999 case studies and sensitivity experiments. Conclusions and discussions are provided in Section 5.

\section{Observational data}

Three types of observational data including surface meteorological data, surface energy fluxes, and atmospheric sounding data are used in this study for evaluating the regional climate simulation of the 1998 and 1999 East Asian summer monsoon. Meteorological data including surface temperature measured at $2 \mathrm{~m}$ above the surface, and precipitation, are available for 17 surface stations within the HUBEX $\alpha$-scale region shown in Fig. 1. At the Shouxian station (latitude/longitude: $32.33^{\circ} \mathrm{N} / 116.47^{\circ} \mathrm{E}$ ) within the HUBEX $\gamma$-scale region (Fig. 1), surface energy fluxes were measured during the 1998 and 1999 Intensive Observing Periods (IOPs) with two independent measurement systems: the Bowen Ratio (BR) and Eddy Correlation (EC) methods. However, because of the heavy rain during the Meiyu season in the region, very few EC measurements can be used. In addition, as most of the available EC measurements did not coincide temporally with measurements of net radiation, the $\mathrm{BR}$ measurements are used in this study to provide a more complete description of the surface energy budget.

Figure 2 shows the partition of the observed surface energy budgets at Shouxian, measured by the BR method for 1998 and 1999. There is a total of 34 days with 20 or more sets of hourly data available each day between 3 June and 24 August of 1998. Similarly, a total of 24 days, with 20 or more sets of hourly data each day, were available between 25 June and 23 July of 1999. During 1998, the net radiation has a daily maximum that ranges between $200 \mathrm{~W} / \mathrm{m}^{2}$ 

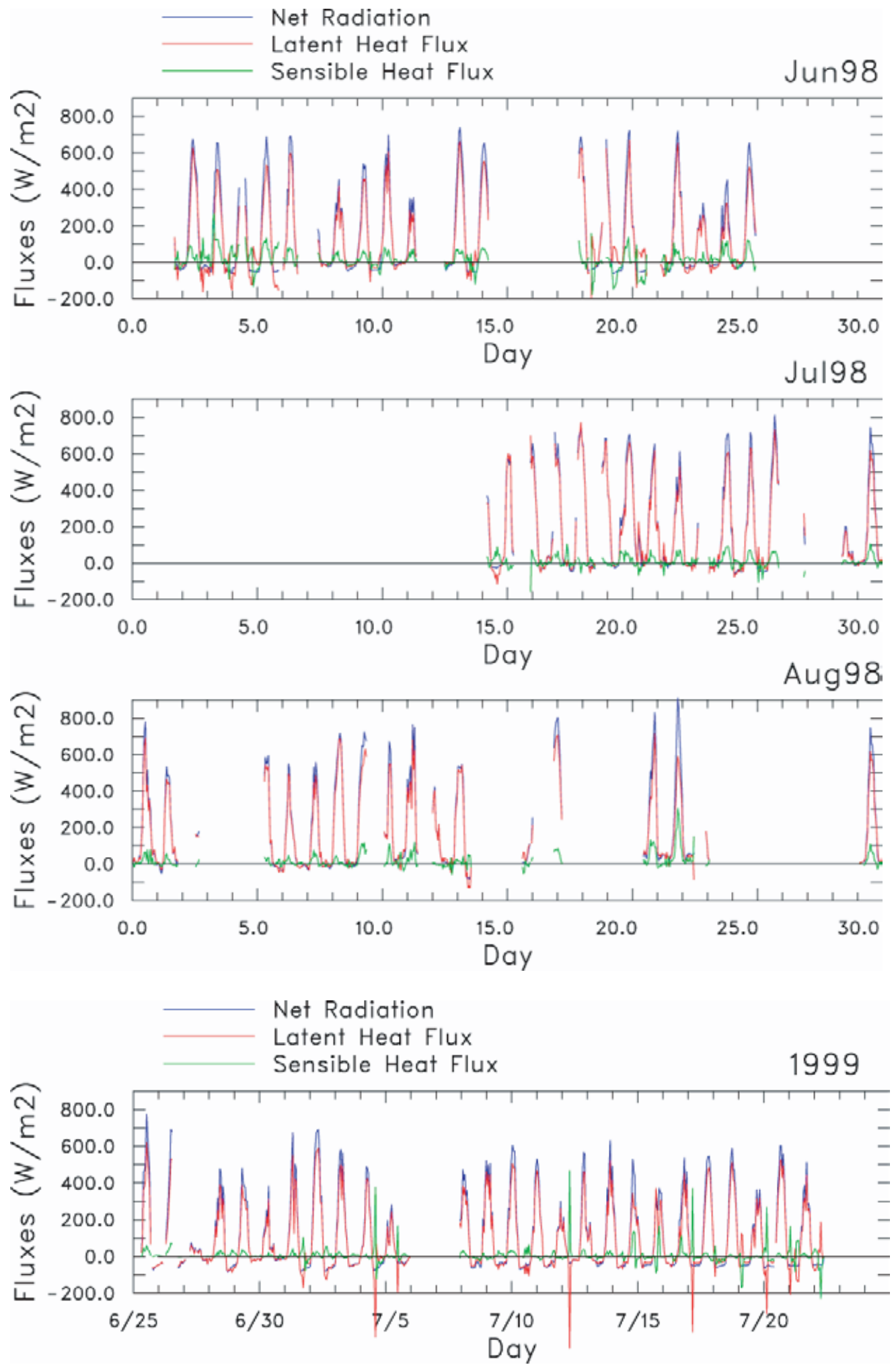

Fig. 2. Hourly mean surface energy fluxes $\left(\mathrm{W} / \mathrm{m}^{2}\right)$ measured by the Bowen Ratio method during the 1998 and 1999 IOPs. Positive values indicate upward/downward fluxes for sensible/latent heat fluxes and net radiation, respectively. 
during cloudy days, and to typically $700 \mathrm{~W} / \mathrm{m}^{2}$ during clear days. The partitioning of total available energy is dominated by the latent heat flux, which has daily maximum fluctuating roughly between 200 to $600 \mathrm{~W} / \mathrm{m}^{2}$. Both the sensible heat flux and ground heat flux (not shown) were very small with daily maximum not exceeding $200 \mathrm{~W} / \mathrm{m}^{2}$. Similar conditions were found during 1999, where radiation and latent heat fluxes dominate the surface energy budget.

Table 1 compares the meteorological conditions and energy fluxes averaged over the period when hourly flux data were available during the two IOPs at the Shouxian station. A major difference can be found in the amount of rainfall, which is much less during 1999 than 1998, when major flooding occurred in the Yangtze River (near $30^{\circ} \mathrm{N}$ ) and Huaihe River basin (near the Shouxian Station shown in Fig. 1). The larger mean rainfall during 1998 is mainly due to higher rainfall intensity, which averaged $37.9 \mathrm{~mm} /$ day based on hourly rainfall larger than $0.1 \mathrm{~mm}$. The rainfall intensity during 1999 is $9.7 \mathrm{~mm} /$ day, which is significantly lower than 1998. There is a much smaller dif-

Table 1. Mean surface meteorological conditions and surface fluxes measured at the Shouxian station during the 1998 and 1999 HUBEX IOPs.

\begin{tabular}{|l|c|c|}
\hline & 1998 & 1999 \\
\hline Surface temperature $\left({ }^{\circ} \mathrm{C}\right)$ & 27.0 & 25.1 \\
\hline Rainfall (mm/day) & 2.21 & 0.48 \\
\hline Rainfall intensity (mm/day) & 37.9 & 9.7 \\
\hline Rain frequency $(\%)$ & 5.8 & 4.9 \\
\hline Surface wind speed (m/s) & 2.8 & 2.9 \\
\hline Surface wind direction & 153.5 & 146.9 \\
\hline Surface net radiation $\left(\mathrm{W} / \mathrm{m}^{2}\right)$ & 177.6 & 107.1 \\
\hline Sensible heat flux $\left(\mathrm{W} / \mathrm{m}^{2}\right)$ & 15.6 & 4.1 \\
\hline Latent heat flux $\left(\mathrm{W} / \mathrm{m}^{2}\right)$ & 159.7 & 91.5 \\
\hline Total cloud fraction $(\%)$ & 62.0 & 73.0 \\
\hline Low cloud fraction $(\%)$ & 20.0 & 21.0 \\
\hline Frequency of clear sky $(\%)$ & 29.0 & 22.0 \\
\hline
\end{tabular}

ference between the frequencies of rain during the two IOPs. In addition, the hourly rainfall measurements reveal a major difference between the day time rainfall, which averaged roughly 2.9 and $0.8 \mathrm{~mm} /$ day during 1998 and 1999 respectively, but night time rainfall was similar during the two years.

Comparing the surface fluxes measured during the 1998 and 1999 IOPs, the net radiation is much lower during 1999. With higher total cloud fraction during 1999 than 1998 by 11\%, the clear sky frequency, as calculated based on hourly total cloud cover less than $10 \%$, is lower during 1999 than 1998 by 7\%. The higher total cloud fraction, larger number of cloudy periods, and possibly larger cloud thickness/cloud optical depth, may explain the much lower net radiation measured in 1999. It is important to note that mean rainfall is not a useful indicator of mean cloudiness and net radiation in regions where rainfall events are convective and sporadic. As the large mean rainfall during 1998 is mainly related to the higher rainfall intensity, rather than rain frequency, it is possible to have both larger mean rainfall, and larger net radiation as measured during the 1998 field experiment than 1999. Driven by the higher net radiation, the latent heat and sensible heat fluxes during 1998 were higher during 1999. The much higher day time rainfall amount during 1998 than 1999 is consistent with the higher surface energy fluxes that increase the likelihood of convection.

Besides observational data at the 17 surface meteorological stations and the Shouxian flux station, we also used data from 21 sounding stations within the HUBEX $\alpha$-scale region for 1998 (Fig. 1). These data include standard twice per day rawinsonde soundings with two additional soundings per day during the IOP (June 5-July 22). These data were used in a sensitivity experiment in which sounding measurements were used to constrain the model simulated atmospheric conditions, using data assimilation as described in more detail below.

\section{Regional climate simulations}

\subsection{Model description}

Regional climate simulations were performed using an RCM based on the Penn State/NCAR Mesoscale Model MM5 (Grell et al. 1993). Various versions of MM5 (e.g., Giorgi et al. 1993; 
Leung and Ghan 1998; Leung et al. 1999) have been used in the past for modeling regional climate of different geographical regions. The model was found to be stable for long-term simulation, and produce results comparable to the large-scale features of the global analyses, or global climate models used to drive the regional model. The model further produced regional climate features that were comparable to observations at the regional scale (e.g., Leung et al. 2003a and 2003b). The current version (Version 3) of MM5 has almost all the capability needed to perform climate simulation. It includes different options of physics parameterizations such as longwave and shortwave radiation, cloud microphysics, cumulus and shallow convection, turbulence transport, and land surface processes. Lateral and lower boundary conditions can be updated regularly based on large-scale conditions.

The climate simulations reported in this study were performed using the Dudhia shortwave radiation (Stephens et al. 1984), the Rapid Radiative Transfer Model (RRTM) for longwave radiation (Mlawer et al. 1997), the Grell convective parameterization (Grell 1993), the Reisner mixed phase cloud microphysics scheme (Reisner et al. 1998), the counter gradient turbulence transport scheme (Hong and Pan 1996), a shallow convection scheme, and the Oregon State University Land Surface Model (Chen and Dudhia 2001). Sensitivity experiments with different choices of physics parameterizations suggest that the results using the CCM2 radiation (Briegleb 1992), versus the Dudhia shortwave and the RRTM longwave scheme are similar provided that the CCM2 radiation scheme is modified to use the cloud amounts simulated by the convection and cloud microphysics schemes, rather that prescribed based on temperature and relative humidity, as was implemented in earlier versions of MM5. Results using the latter approach showed very large cool and dry bias and compared much less favorably with observations. The simulations reported in this study used the Dudhia shortwave and RRTM longwave radiation schemes. Sensitivity experiments further showed that results were quite sensitive to the choice of convective parameterizations, which will be discussed in the sensitivity experiments described below.

\subsection{Numerical experiments}

The RCM described above was used to simulate the 1998 and 1999 East Asian summer monsoon conditions, with the model domain shown in Fig. 1, using 23 vertical levels with the model lowest level prescribed at the sigma level of 0.995 , which corresponds roughly to $40 \mathrm{~m}$ above the surface, and horizontal spatial resolution of $60 \mathrm{~km}$ and a total of $65 \times 85$ grid cells. In all the simulations, lower and lateral boundary conditions for the RCM were provided by the European Centre for Mediumrange Weather Forecast (ECMWF) Tropical Ocean and Global Atmosphere (TOGA) global analysis dataset. These boundary conditions include large-scale temperature, atmospheric moisture, winds, geopotential height, surface pressure, and sea surface temperature, all spatially interpolated horizontally and vertically from the analysis grids and vertical levels to that of the RCM. Lateral boundary conditions were assimilated into the regional simulation using nudging within a buffer zone of 15 grid points on each side. The nudging coefficient follows the exponential function of distance from the lateral boundary described by Giorgi et al. (1993). The simulation was initialized on 1 April of 1998 and 1999 with lateral and lower boundary conditions updated every 12 hours based on the analysis through the end of August for each year. Only simulation outputs for 1 May through 31 August were used in the model evaluation described below.

Two additional simulations were performed to further evaluate the physics parameterizations used in the RCM, and to examine the sensitivity of regional climate simulations to physics parameterizations. As discussed by Jakob (2003), one way to evaluate physics parameterizations of climate models is to apply the models in short-range numerical weather prediction (NWP), to avoid the problem of building up large systematic model errors in the large-scale circulation. Jakob (1999) used this approach to evaluate the ECMWF cloud parameterization. In our first sensitivity experiment, a similar approach is used to limit errors in the simulated large-scale circulation, which could result from biases in the representations of physical processes, errors in the numerical techniques, treatments of the lateral boundary conditions, or a combination of all three. To 
isolate model biases associated physics parameterizations, a sensitivity experiment was performed for the 1998 case study where the model-simulated large-scale atmospheric circulation, including temperature, water vapor mixing ratio, and winds within the HUBEX $\alpha$ scale region were constrained by the soundings taken at 21 locations within the HUBEX domain (see Fig. 1), using four dimensional data assimilation technique (FDDA). During nonIOP days, soundings were launched twice per day at standard sounding times (00 and 12 UTC), while during HUBEX IOP (June 5-July 22), two additional soundings were released at 06 and 18 UTC. All sounding variables including temperature, relative humidity, and wind speed and direction were used in the FDDA for the whole simulation period.

We adopted a continuous dynamical assimilation technique where artificial tendency terms based on the difference between the simulated and observed states are added to the governing model equations to gradually "nudge" the model state toward the observations. As described by Grell et al. (1993), during each model time step, differences between the simulated and observed states were computed at the observation locations (the 21 sounding sites), and analyzed back to the grids in a region surrounding the observations. The soundings were vertically interpolated to the model sigma levels at each observation location prior to the simulation. A comparison of the precipitation and surface energy fluxes in the control simulation and the simulation with FDDA should show model biases that are more directly related to the physics parameterizations, since FDDA was used to maintain a close agreement between the simulated and observed large-scale atmospheric conditions. An alternative and less expensive approach for evaluating the physics parameterizations using observations from field experiments, is to apply a single column model version of the RCM with boundary conditions prescribed based on observations (such as temperature, relative humidity, and winds). Since a single column model version of MM5 is not readily available, the FDDA approach provides a useful alternative to evaluating physics parameterizations used in MM5.

To examine the sensitivity of regional simu- lations to cloud parameterizations, a second sensitivity experiment was performed for the 1999 case to examine the effects of convective parameterizations on the regional climate simulations. In the $\mathrm{KF}$ simulation, the Grell scheme used in the control simulation was replaced by the Kain-Fritsch scheme (Kain and Fritsch 1993). In the Grell cumulus convection scheme, clouds are maintained by the updraft and downdraft with no mixing between the cloud and environment except at the top and bottom of the circulations. The originating levels of updraft and downdraft are the levels of maximum and minimum ambient moist static energy. Convection is triggered when a parcel lifted from the updraft originating level attains moist convection as determined by moist static energy. The KF scheme uses a classical approach to remove convective available potential energy (CAPE) by vertical reorganization of mass. This method includes detrainment of mass and moisture from deep convective clouds, and represents the exchange of mass between cloud and environment. Convection is triggered based on parcel buoyancy at the lifting condensation level. Because of differences in closure assumptions and trigger functions, large differences can often be found in the amount and spatial distribution of precipitation simulated by different convection schemes. The purpose of this sensitivity experiment is not to find the optimal cloud parameterizations for our simulations, but to elucidate potential uncertainty in simulating surface climate and surface energy fluxes by using different convection parameterizations.

\section{Results}

\subsection{8 summer}

To examine the general features of the 1998 summer monsoon, Fig. 3 shows the spatial distribution of monthly mean precipitation, based on observations and the control simulation. Observations were based on surface station measurements over China, Japan, and other neighboring countries. No attempts were made to include observations of precipitation over the ocean, which are typically only available at coarser spatial resolution. The control simulation captured the spatial distribution and the northward progression of the monsoon rain belt quite well. As described by Ding et al. (2001), 

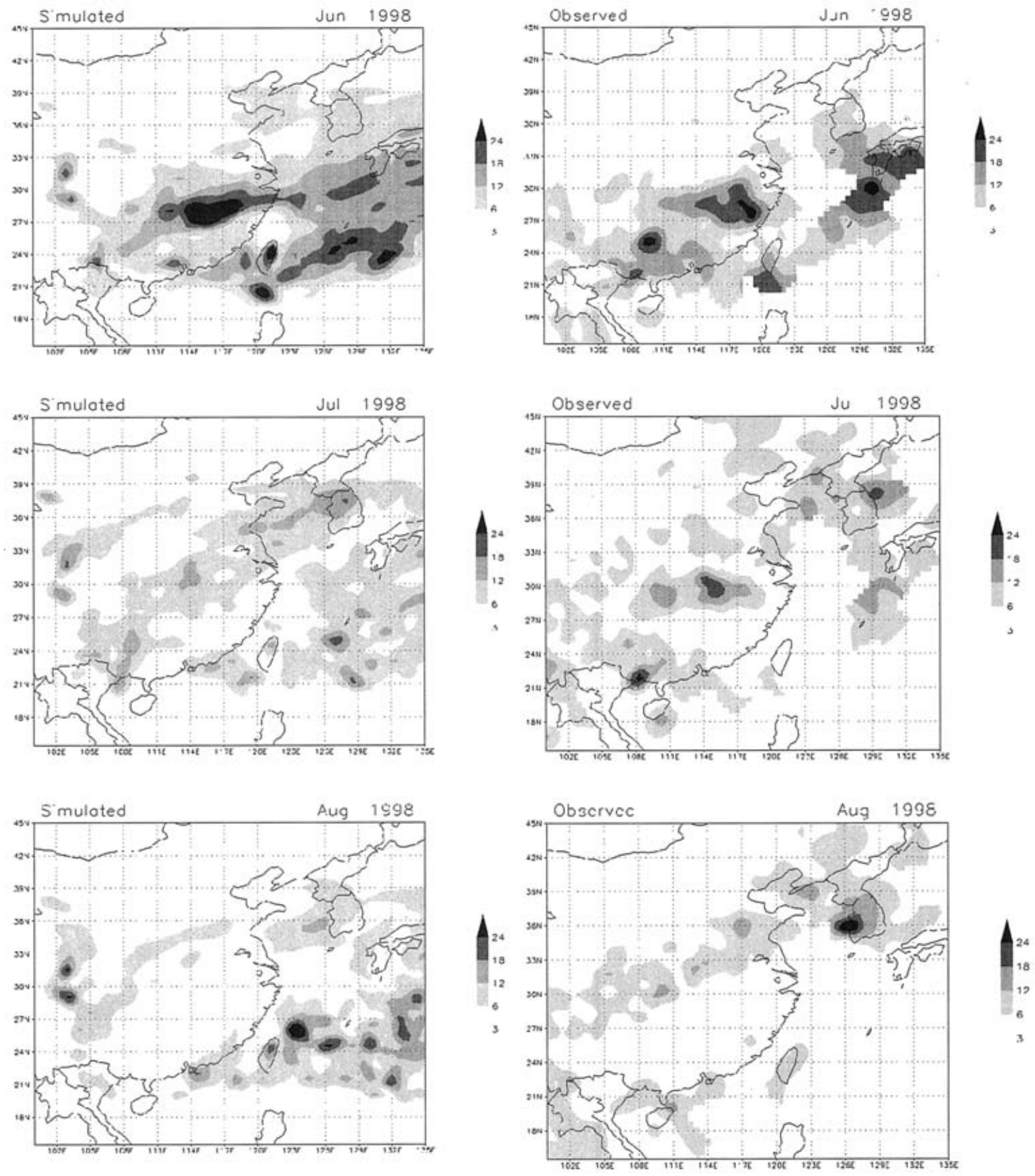

Fig. 3. Spatial distribution of observed and simulated monthly mean rainfall (mm/day) for June, July, and August of 1998 for the control simulation. Observations are spatially interpolated from station measurements over land and island locations. 
the first stage of the 1998 Meiyu season occurred between June 11 and 27, with heavy rainfall to the south of the Yangtze River. The model correctly simulated the intensity and location of the rain belt, which is roughly defined by an elongated region, with more concentrated rainfall, very well in June. During the second stage of the Meiyu season, the Meiyu front was maintained over the Huaihe River basin for about one week in early July, and caused major flooding in that area. During the third stage, the Meiyu front retreated back to the south of the Yangtze River basin from July 17 to early August. Both the observed and simulated July monthly mean rainfall reflects the spatial characteristics of rainfall in the Huaihe River, as well as south of the Yangtze River. In August, the Meiyu frontal rain belt had a narrower banded structure located further north near the Huaihe River basin. Overall, the model realistically simulated the spatial structure and temporal variations of the observed rainfall.

Characteristics of the Meiyu season over the Huaihe River basin were well observed by the 1998 HUBEX IOP. Figure 4 compares the observed and simulated daily precipitation, and daily maximum and minimum surface tem-
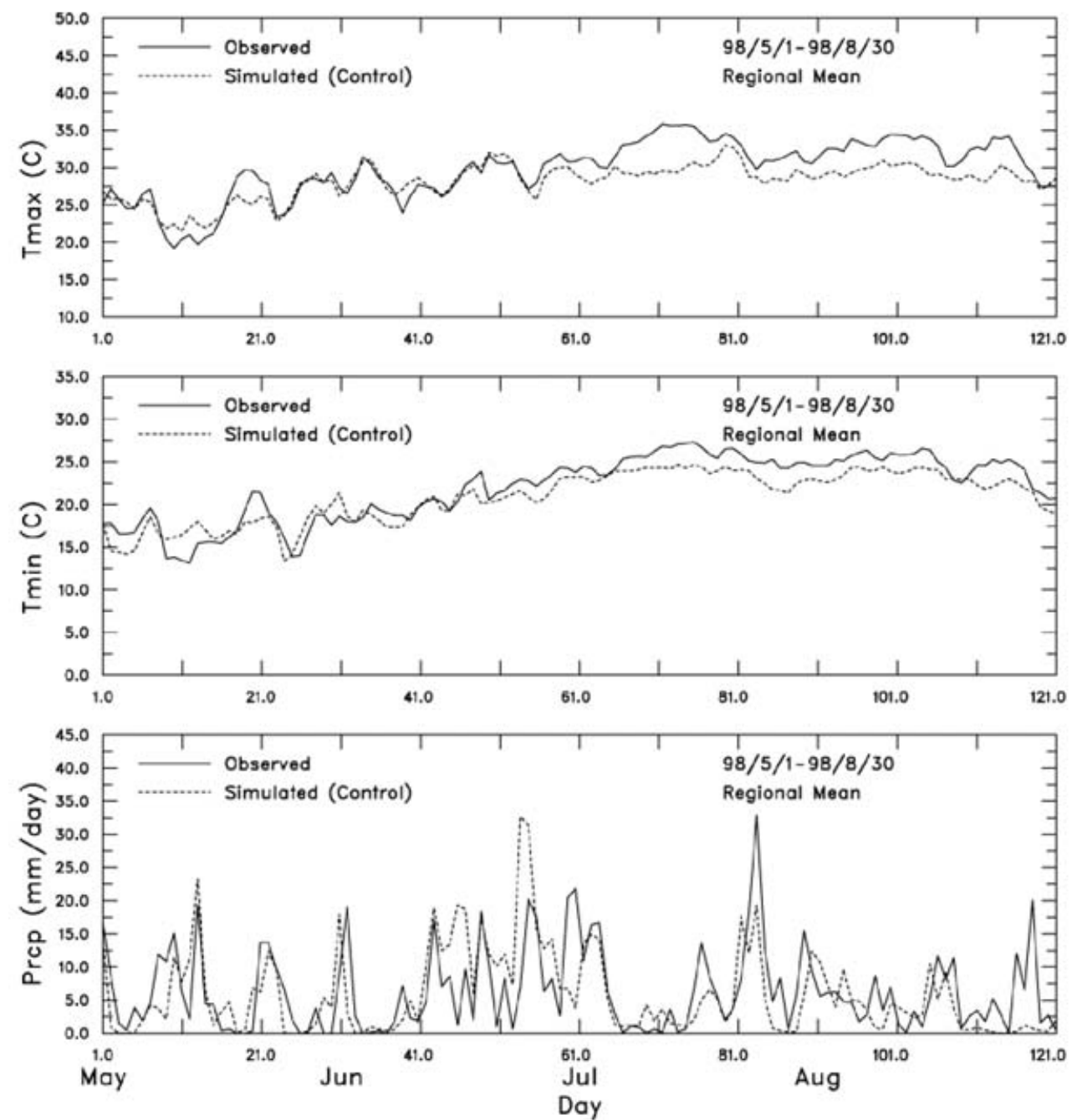

Fig. 4. Observed and simulated daily maximum and minimum surface temperature (Tmax/Tmin) and precipitation (Prcp) for 1998 averaged over the 17 surface meteorological stations shown in Fig. 1 for the control simulation. 
perature, averaged over the 17 surface stations shown in Fig. 1 between 1 May and 31 August of 1998. For each surface station, model simulations for the nearest four grid cells are interpolated bi-linearly to the station location for comparison. Surface air temperature from the RCM was calculated based on a simple weighting of surface skin temperature and air temperature at the model's lowest level (near $40 \mathrm{~m}$ ) following Dickinson et al. (1986), which provides a good approximation to the $2 \mathrm{~m}$ air temperature for comparison with the observed surface temperature. Because the 17 surface stations are located in areas with relatively smooth and low elevation, differences between the observed and simulated surface temperature caused by differences between the station and model elevation are minor. Intense precipitation above $15 \mathrm{~mm} /$ day was observed mainly during the second stage of the Meiyu season (June 28-July 3), when the Meiyu front was maintained over the Huaihe River basin. The model generally captured the episodic rainfall events quite well. However, the timing and intensity of simulated daily precipitation during the second stage, did not match the observation on a daily basis, because of phase errors and other model biases.

For surface temperature, the simulated daily maximum surface temperature $\left(T_{\max }\right)$ was comparable to the observed during May and June, but became much cooler than the observed during July and August by as much as $6^{\circ} \mathrm{C}$. Incidentally, model biases were small during the heavy rainfall events between June 28 and July 3 , and the largest negative biases in July did not coincide temporally with any large precipitation events. This suggests that model biases in $T_{\max }$ were not related to rainfall intensity. There were much less temporal variations in the model simulation than the observations. Biases in the simulated daily minimum surface temperature $\left(T_{\min }\right)$ were generally smaller than the biases of $T_{\max }$. Similar to the trends in $T_{\max }$, there was also warm bias in $T_{\min }$ during May and cool bias in July and August.

Similar to Fig. 4, the comparison of observed and simulated $T_{\max }, T_{\min }$, and rainfall for the FDDA experiment is shown in Fig. 5. With FDDA, the simulated rainfall is much closer to the observed in terms of both timing and in- tensity. Furthermore, model biases were much reduced in both $T_{\max }$ and $T_{\min }$ with the use of FDDA. The simulated $T_{\max }$ captured the large temporal variations during May and smaller biases than the control simulation were found during the whole period except June, where the model became too warm. Since the net surface radiation in the control and FDDA simulations were similar in June (Fig. 6), the larger warm bias in the FDDA simulation may be related to the dryer soil conditions, since the FDDA simulation consistently produced less rainfall before and during this time period. Model biases in $T_{\min }$ were reduced throughout the simulation period. The general reduction in model biases with the use of FDDA suggests that errors in simulating the large-scale atmospheric conditions, which could be related to errors in the numerical methods and/or physics parameterizations, had important effects on the simulation of rainfall and surface temperature.

Figure 6 compares the observed and simulated daily mean net radiation, sensible heat flux, and latent heat flux at the Shouxian station. The model simulated fluxes were interpolated bi-linearly from the four grid cells closest to the Shouxian station for comparison. Because the RCM cannot resolve features with spatial scale smaller than $120 \mathrm{~km}$, comparison of simulated and observed fluxes at a single station is problematic, especially when large surface heterogeneity exists. Since flux measurements were only available at the Shouxian station and no information was provided on the heterogeneity of the surface conditions during the IOPs, this comparison can only provide a qualitative evaluation of the model simulated surface fluxes.

From Fig. 6, there were large variations in the observed, as well as simulated net radiation during the summer period. Although model biases were relatively small in June, larger negative biases were found in July and August. With FDDA, the negative biases were reduced but remained quite significant. These biases are likely related to biases in simulating the vertical distribution of clouds (including cloud water and cloud ice), and cloud optical depths, which could be reduced, but not totally eliminated, when FDDA was used to constrain the large-scale circulation. It should also be noted, however, from Fig. 2 that the negative biases 

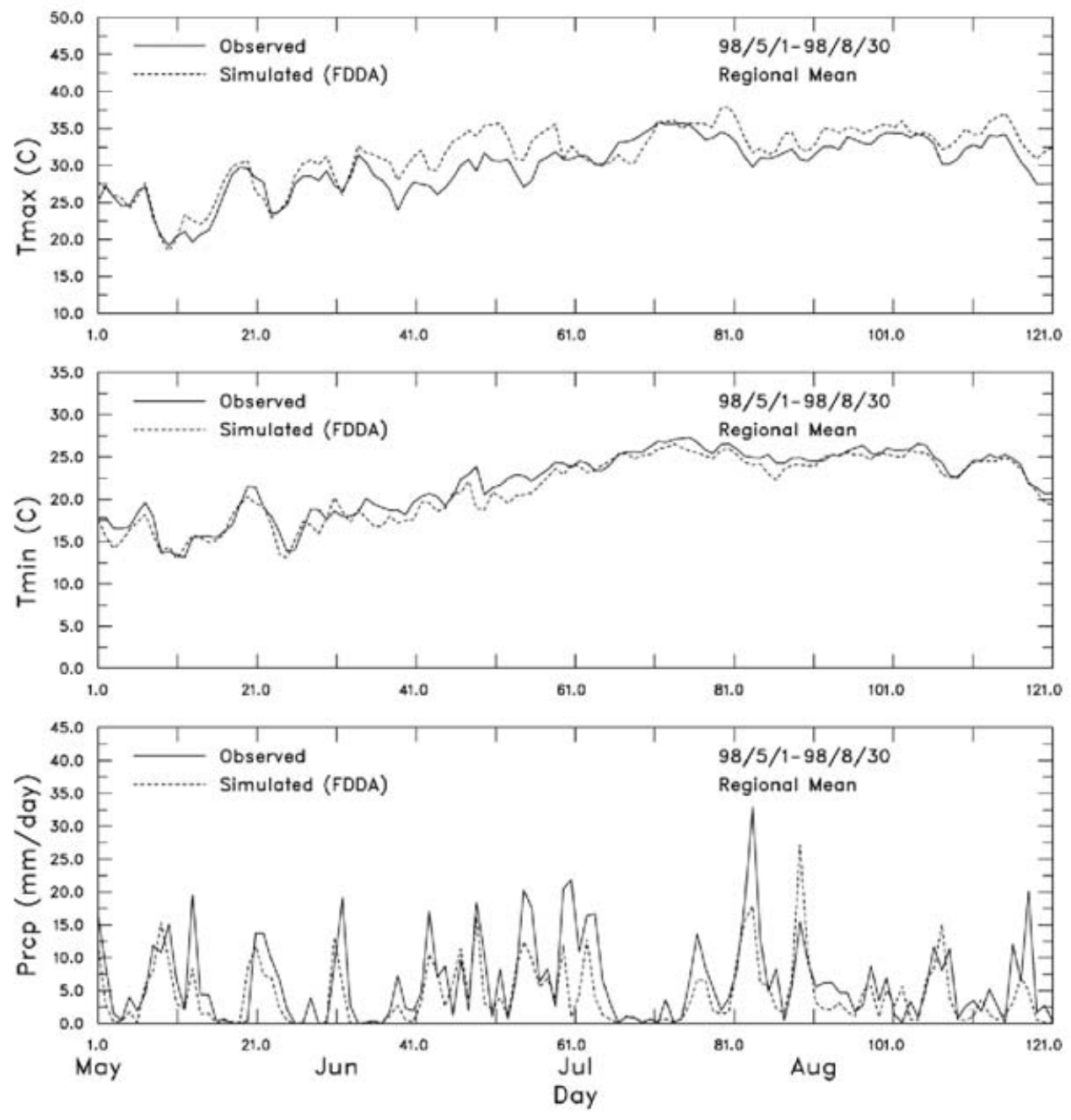

Fig. 5. Same as Fig. 4, but for the FDDA simulation.

may also be related to positive biases in the observed net radiation, which became increasingly by more apparent in late July and August, with frequent occurrence of positive net radiation during night time between 20 and $50 \mathrm{~W} / \mathrm{m}^{2}$.

Comparing the sensible and latent heat fluxes in Fig. 6 reveals that the RCM also simulated latent heat flux that was too small, especially in July and August. The sensible heat flux, however, was well simulated in July and August, which suggests that the negative bias in latent heat flux during that time period was mainly related to errors in the net radiation. On the contrary, the negative biases in latent heat flux, positive biases in sensible heat flux, and small biases in net radiation in mid-to-late June suggest that energy was partitioned differently between sensible and latent heat fluxes in the observation and simulation. However, such discrepancy between the observed and simulated fluxes may simply arise because of subgrid variations in meteorological conditions, or land cover characteristics. Table 2 summarizes the model root mean square error and mean bias in $T_{\max }, T_{\min }$, rainfall, and the surface energy fluxes at the Shouxian station for the control and FDDA simulations averaged over May through August of 1998 when flux measurements were available. 

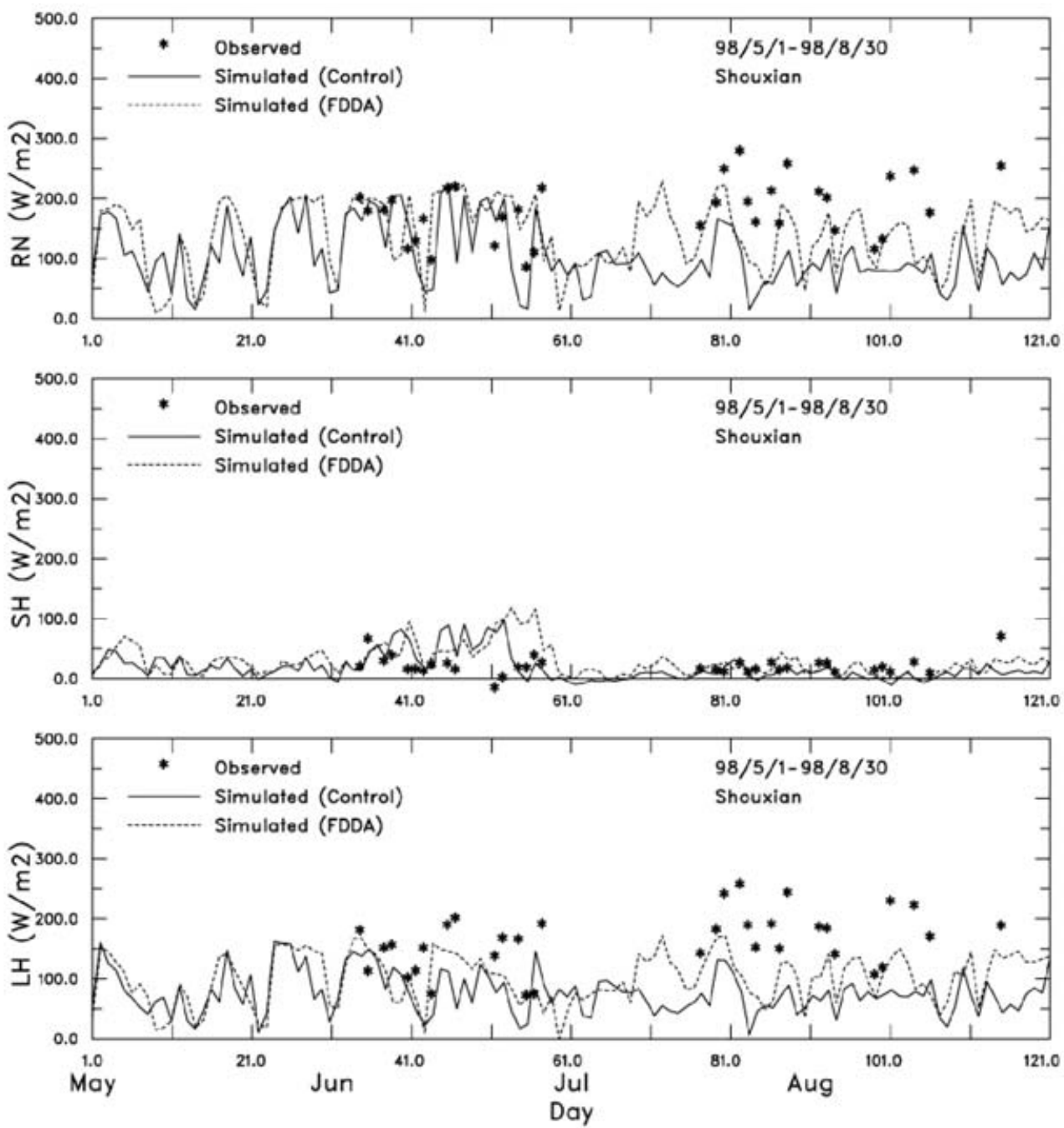

Fig. 6. Comparison of the observed and simulated daily mean surface net radiation (RN), sensible heat flux $(\mathrm{SH})$, and latent heat flux $(\mathrm{LH})$ at the Shouxian station. Results from the control and FDDA simulations are shown by the solid and dashed curves, respectively.

\subsection{9 summer}

As discussed by Ding et al. (2001), the summers of 1998 and 1999 differ in several aspects, including the location of the subtropical high, development of the polar vortex, and location of the frontal rain belt. During the 1999 Meiyu season, the major rain belt propagated to the middle and lower reaches of the Yangtze River and southern part of Japan, causing severe flooding in June and July. Figure 7 shows the spatial distribution of the observed and control simulation of monthly mean precipitation. The major rain belt in June was well captured by the regional model. However, the July simulated rainfall was more widespread and much further north than was observed. In August, the model simulated well the rainfall spatial distribution, but lacked the intensity. Comparing the 1998 and 1999 summer, there was more precipitation in southern China during May and August, and less precipitation north of the Yangtze River during 1999. The regional model realistically simulated the major contrast between the two summer seasons that resulted in record high precipitation in the Huaihe basin in 1998, and record high precipitation in the Yangtze River in 1999.

Similar to Fig. 7, the spatial distribution 
Table 2. Model root mean square error and mean bias (in parenthesis) in the daily surface meteorological conditions and surface energy fluxes at the Shouxian station for the control and FDDA simulations during 1998 IOP.

\begin{tabular}{|l|c|c|}
\hline & $\begin{array}{c}\text { Control } \\
\text { Simulation }\end{array}$ & $\begin{array}{c}\text { FDDA } \\
\text { Simulation }\end{array}$ \\
\hline Tmax $\left({ }^{\circ} \mathrm{C}\right)$ & $4.2(-0.4)$ & $4.2(2.6)$ \\
\hline Tmin $\left({ }^{\circ} \mathrm{C}\right)$ & $2.1(-1.3)$ & $1.6(-0.4)$ \\
\hline $\begin{array}{l}\text { Rainfall } \\
(\mathrm{mm} / \text { day })\end{array}$ & $16.1(4.8)$ & $7.4(2.1)$ \\
\hline $\begin{array}{c}\text { Net radiation } \\
\left(\mathrm{W} / \mathrm{m}^{2}\right)\end{array}$ & $91.0(-63.1)$ & $61.9(-23.2)$ \\
\hline $\begin{array}{c}\text { Sensible heat } \\
\text { flux }\left(\mathrm{W} / \mathrm{m}^{2}\right)\end{array}$ & $36.9(10.3)$ & $43.5(22.2)$ \\
\hline $\begin{array}{c}\text { Latent heat } \\
\text { flux }\left(\mathrm{W} / \mathrm{m}^{2}\right)\end{array}$ & $92.7(-79.4)$ & $67.7(-52.8)$ \\
\hline
\end{tabular}

of monthly mean precipitation for the $\mathrm{KF}$ simulation is shown in Fig. 8. The KF scheme generally produced more precipitation than the Grell scheme, and the spatial distribution was in better agreement with observations. There is a large contrast between the rainfall in July simulated by the two convection schemes, with the KF simulation showing more widespread precipitation in southern China, rather than north of the Yangtze River. In August, the KF simulation also captured more realistic precipitation intensity south of the Yangtze River than the control simulation.

Figure 9 shows the observed and simulated daily maximum/minimum surface temperature and daily total rainfall averaged over the 17 stations shown in Fig. 1, based on the control simulation, and rainfall for the $\mathrm{KF}$ simulation was added in the bottom panel. The KF simulation of surface temperature was very similar to the control simulation and therefore not shown. Similar to the 1998 case, cool bias shows up in $T_{\max }$, especially in late July and August, but $T_{\min }$ was well simulated throughout the 1999 summer. Heavy rainfall was observed in the region over several episodes, especially between June 22 and June 29 when precipitation was consecutively above $15 \mathrm{~mm} /$ day each day. The control simulation captured the temporal variations of rainfall quite well, except for a general wet bias. There were stronger agreements between the observed and simulated rainfall during the first half than the second half of the summer.

The rainfall simulated by the $\mathrm{KF}$ scheme matched the observation exceptionally well in May and June. However the simulation failed to produce any precipitation in July and August, during several episodes when rainfall was observed. Furthermore, the timing of precipitation in the control and $\mathrm{KF}$ simulations became quite different in July and August. This suggests that significant differences may have developed between the large-scale circulations of the two simulations during the last two months. On the other hand, during this dryer period of July and August in the HUBEX region, differences between the Grell scheme and $\mathrm{KF}$ scheme in the triggering of convective precipitation, as described in Section 3.1, may also explain the difference in the timing of the precipitation events.

Figure 10 compares the observed and simulated daily mean net radiation, sensible heat flux, and latent heat flux at the Shouxian station. As summarized in Table 3, both the root mean square error and model bias in the control simulations were smaller during 1999 than 1998. The biases in the net radiation and latent heat flux were $-18 \%$ and $-33 \%$ in 1999 , and $-36 \%$ and $-50 \%$ in 1998 respectively in the control simulations (see Table 2 and Table 3 ). There was also a closer agreement between the observed and simulated $T_{\max }$ and $T_{\min }$ during 1999 than 1998. Comparing the control and KF simulation where the only difference is the choice of convection scheme, the KF scheme resulted in lower precipitation, slightly cooler surface temperature, and increase in all components of surface heat fluxes, including net radiation, sensible heat, and latent heat fluxes at the Shouxian station. This results in a change in the sign of the mean bias of the surface net radiation corresponding to an increase of $29 \mathrm{~W} / \mathrm{m}^{2}$ or $27 \%$ difference from the control to the KF simulation, which is consistent with the reduction of rainfall and cloudiness (not shown) in the KF simulation. This shows the strong impacts of cumulus convection schemes on cloud and radiation. 

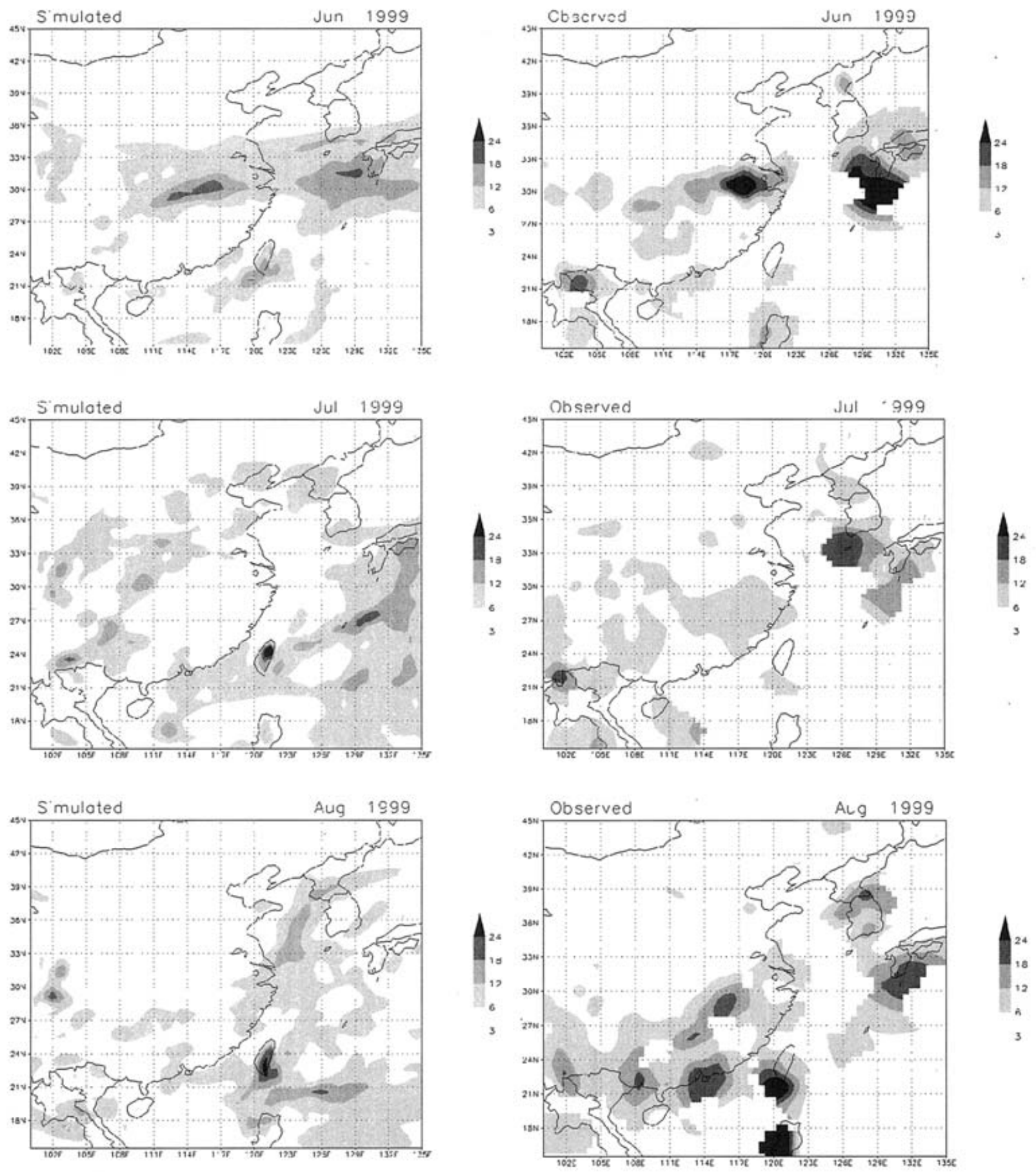

Fig. 7. Spatial distribution of observed and simulated monthly mean rainfall (mm/day) for June, July, and August of 1999 for the control simulation.

\section{Conclusion and discussion}

This study makes use of the HUBEX observations to evaluate how well surface climate, and energy fluxes, can be simulated by regional climate models during two years with extreme flood conditions in the Yangtze and Huaihe River basins. Observations showed large differ- 

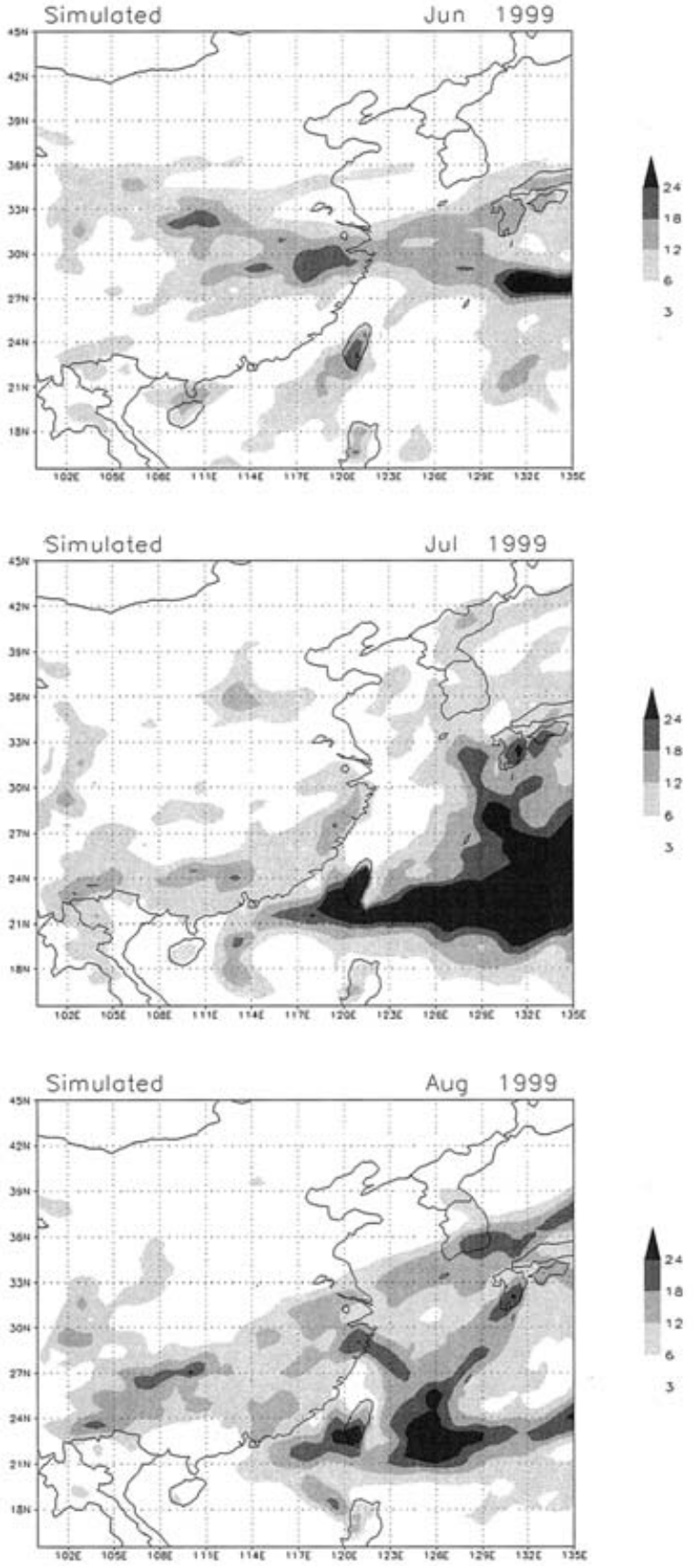

Fig. 8. Spatial distribution of the KF simulation of monthly mean rainfall (mm/day) for June, July, and August of 1999.

ences between the 1998 and 1999 meteorological conditions and surface energy budgets at the Shouxian station during the IOPs. Analyses of the observations showed that 1998 was marked by rainfall events with much higher intensity, but rain frequency was only slightly above that of 1999. Because of more frequent clear days, lower cloud fractions, and possibly lower cloud thickness/optical depth during cloud cover periods, the net radiation measured during 1998 was, on average, about $70 \mathrm{~W} / \mathrm{m}^{2}$ higher than 1999. Our analyses showed that mean rainfall is not a useful indicator of mean cloudiness and net radiation in regions where rainfall is convective and sporadic. In addition, cloud fraction and frequency of cloudy days are probably also not useful indicators of net radiation, because the latter is more strongly affected by cloud amounts and vertical distribution. In a summer convective regime, cloud amounts and vertical distributions could differ significantly during days with similar cloud fractions.

For 1998, although the RCM was able to reproduce the general spatial distribution of monthly mean rainfall, during the summer monsoon season, large discrepancies can be found in comparing the observed and simulated surface climate and energy fluxes in the HUBEX region. By using FDDA, both the root mean square error and mean bias in rainfall were greatly reduced. The improvements in simulating rainfall were related to both reduction in errors of precipitation amount and timing. In the control simulation, a mean bias of $-63 \mathrm{~W} / \mathrm{m}^{2}(-36 \%)$ was found in the simulated surface net radiation, which suggest large errors in simulating clouds in the region. With FDDA, the bias was significantly reduced to $-23 \mathrm{~W} / \mathrm{m}^{2}(-13 \%)$, with corresponding reduction of bias in the latent heat flux. This seems to suggest that at least part of the model bias in simulating net radiation is related to errors in simulating the large-scale circulation, which can affect cloud amount and vertical distribution. In the control simulation, errors in simulating clouds may further amplify errors in the large-scale circulation through feedback effects, as suggested by Leung et al. (1999). In the FDDA simulation, such possible feedback loop was inhibited, which may explain the large difference found between the two simulations.

For 1999, an interesting finding is that model biases in the surface fluxes were much smaller than those in the 1998 control simulation, regardless of the convective parameterizations 

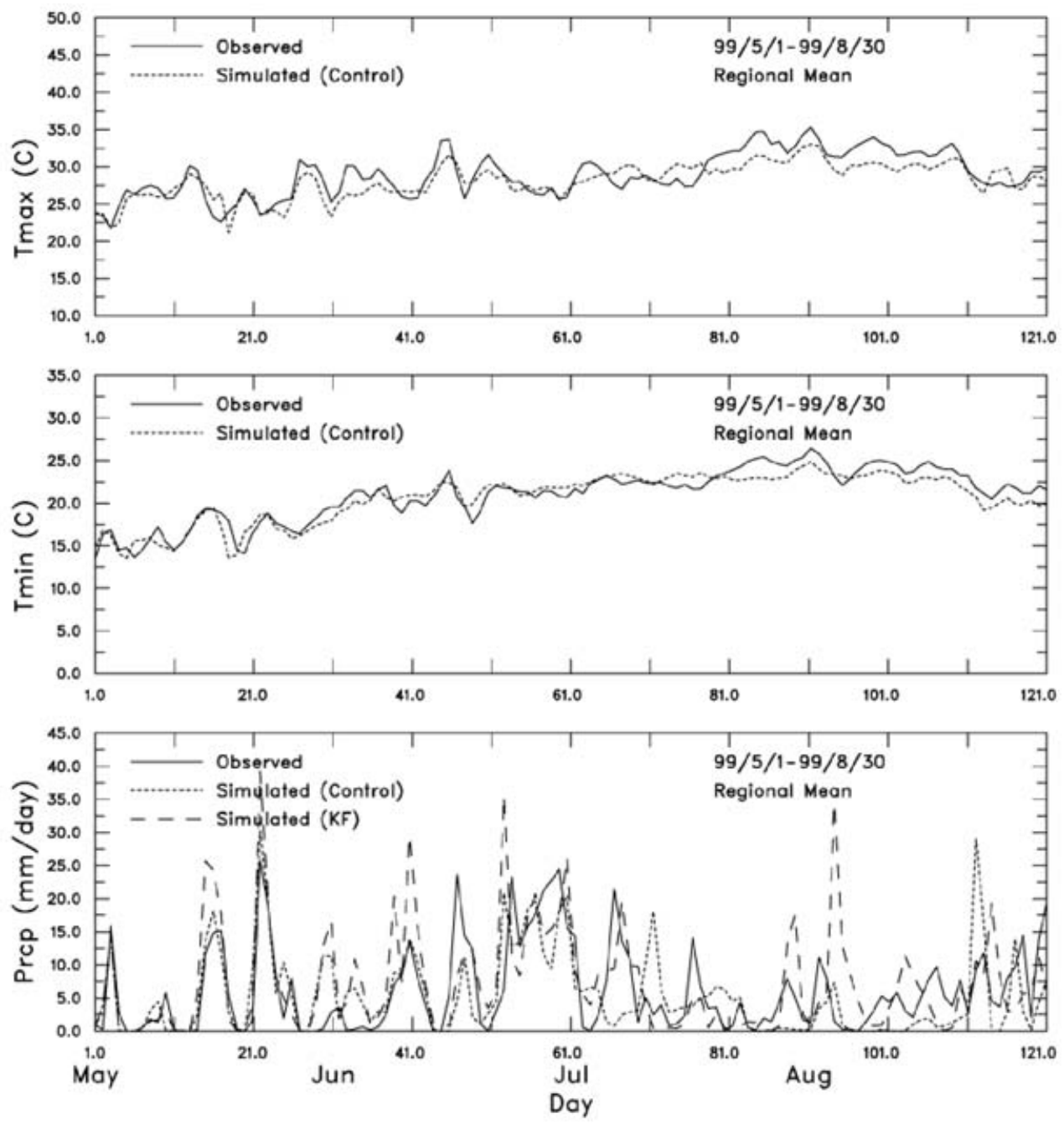

Fig. 9. Observed and simulated daily maximum and minimum surface temperature (Tmax/Tmin) and precipitation (Prcp) for 1999 averaged over the 17 surface meteorological stations shown in Fig. 1. Results are based on the control simulation (short dashed lines) and the KF simulation of rainfall is added in the bottom panel shown by the long dashed line.

used. Observations (Table 1) show that there were larger cloud fraction (mainly associated with mid and high clouds), and smaller surface net radiation during 1999 than 1998. Because the difference between the net surface radiation of the two years is much larger than what may be explained by the relatively small difference in cloud fraction, it is likely that larger differences exist in the cloud optical depth and/ or vertical distribution. Therefore, one possible reason for the smaller bias in the surface net radiation during 1999 is that errors in simulating cloud amounts, and vertical distribution, may have smaller effects on the simulation when large cloud covers are present in both the observation and simulation. That is, correctly simulating cloud amounts and vertical distribution may be less important when clouds are optically thick. It is also possible that there is larger temporal variability in cloud cover during 1998, such that mismatch of cloudy and clear days in the observation and simulation can induce large errors in simulating surface net radiation. Lastly, there may simply be smaller biases in simulating the large-scale circulation during 1999 than 1998 that result in better simulation of clouds. These factors are likely related and have all played a role leading 

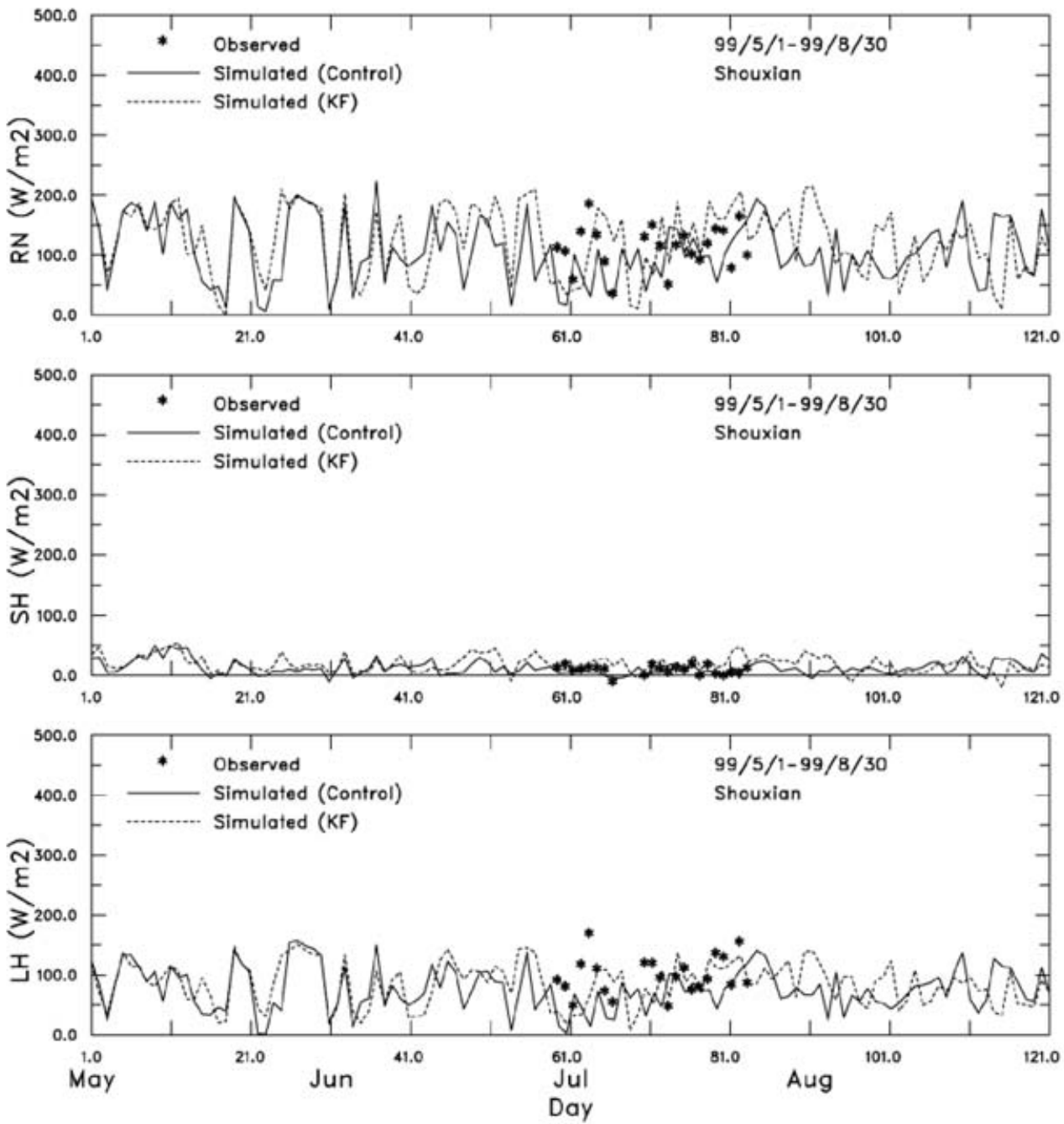

Fig. 10. Comparison of the observed and simulated daily mean surface net radiation (RN), sensible heat flux $(\mathrm{SH})$, and latent heat flux $(\mathrm{LH})$ at the Shouxian station. Results from the control (solid) and $\mathrm{KF}$ (dashed) simulations are shown by the solid and dashed curves.

to different model skill in simulating the 1998 and 1999 climate conditions.

To answer some of the questions raised by this model evaluation study, more numerical experiments and analyses are planned to further investigate the differences between the control and FDDA simulations of 1998, and the differences between the 1998 and 1999 simulations. These may include analyses of the vertical distribution of cloud amounts, and atmospheric heating rates and their temporal variability, evaluation of the large-scale circulation, and analyses of the diurnal cycles of the surface energy fluxes based on hourly data.
More numerical experiments can be performed with the FDDA, using nudging with the observed atmospheric variables (e.g., temperature, relative humidity, and winds) one at a time, to determine their individual impacts. In addition, simulations using the offline land surface model used in the RCM, driven by the observed meteorology, can help isolate errors related to the treatments of land surface processes.

The ability to investigate various issues raised by this study has been limited by the availability of surface flux measurements over a single location. This limitation can be signifi- 
Table 3. Model root mean square error and mean bias (in parenthesis) in the daily surface meteorological conditions and surface energy fluxes at the Shouxian station for the control and KF simulations during the 1999 IOP.

\begin{tabular}{|l|c|c|}
\hline & $\begin{array}{c}\text { Control } \\
\text { Simulation }\end{array}$ & $\begin{array}{c}\text { KF } \\
\text { Simulation }\end{array}$ \\
\hline Tmax $\left({ }^{\circ} \mathrm{C}\right)$ & $2.4(-0.3)$ & $3.4(-1.4)$ \\
\hline Tmin $\left({ }^{\circ} \mathrm{C}\right)$ & $1.6(0.9)$ & $1.7(-0.8)$ \\
\hline $\begin{array}{c}\text { Rainfall } \\
(\mathrm{mm} / \text { day })\end{array}$ & $14.0(7.8)$ & $7.9(2.3)$ \\
\hline $\begin{array}{c}\text { Net radiation } \\
\left(\mathrm{W} / \mathrm{m}^{2}\right)\end{array}$ & $52.9(-20.1)$ & $74.6(8.8)$ \\
\hline $\begin{array}{c}\text { Sensible heat } \\
\text { flux }\left(\mathrm{W} / \mathrm{m}^{2}\right)\end{array}$ & $9.8(4.7)$ & $21.8(14.2)$ \\
\hline $\begin{array}{c}\text { Latent heat } \\
\text { flux }\left(\mathrm{W} / \mathrm{m}^{2}\right)\end{array}$ & $49.7(-30.9)$ & $50.3(-12.4)$ \\
\hline
\end{tabular}

cant if large spatial variability of surface fluxes exist in the region. Improving the spatial coverage of flux measurements is an important consideration for future field experiments that aim to study hydrological cycles of the monsoon region. In addition, this study is also limited by possible errors in the observed surface fluxes, such as incidences of positive night time net radiation during July and August of 1998, which complicate model evaluation and limit the usefulness of more detailed analyses.

\section{Acknowledgements}

This study was supported by the U.S. Department of Energy (DOE) as part of the bilateral agreement between DOE and China Meteorological Administration (CMA) on regional climate research. We thank Prof Yihui Ding of CMA for providing the HUBEX data used in this study. Pacific Northwest National Laboratory is operated for the U.S. DOE by Battelle Memorial Institute under Contract DE-AC0676RLO 1830.

\section{References}

Briegleb, B.P., 1992: Delta-Eddington approximation for solar radiation in the NCAR Community Climate Model. J. Geophys. Res., 97, 76037612 .
Chen, F., and D., Dudhia, 2001: Coupling an advanced land surface-hydrology model with the Penn State-NCAR MM5 modeling system. Part I: Model implementation and sensitivity. Mon. Wea. Rev., 129, 569-585.

Dickinson, R.E., P.J. Kennedy, A. Henderson-Sellers, and M. Wilson, 1986: Biosphere-Atmosphere Transfer Scheme (BATS) for the NCAR Community Climate Model, NCAR Tech. Note, NCAR/TN-275+STR, Natl. Cent. for Atmos. Res., Boulder, Colo.

Ding, Y.H., X.L. Shi, Y.M. Liu, and Q.Q. Li, 2003: Sensitivity experiments and the experimental use of the nested regional climate model in the seasonal prediction during flooding seasons in China. J. Meteor. Soc. Japan (submitted). -, Y. Zhang, M. Qiang, and H. Guoquan, 2001: Analysis of the large-scale circulation features and synoptic systems in East Asia during the intensive observation period of GAME/ HUBEX. J. Meteor. Soc. Japan, 79(1B), 277300. , 1994: Monsoons over China. Kluwer Academic Publisher, Dordrecht/Boston/London, 419pp.

GAME/HUBEX Office, 1997: Huaihe River Basin Experiment (GAME/HUBEX). Published by National Climate Center of China, 25pp.

GAME International Science Panel (ISP), 1998: GEWEX Asian Monsoon Experiment (GAME) Implementation Plan. Published by GAME International Project Office, 136pp.

Giorgi, F., M.R. Marinucci, G.T. Bates, and G. De Canio, 1993: Development of a secondgeneration regional climate model (RegCM2). Part II: Convective processes and assimilation of lateral boundary conditions. Mon. Wea. Rev., 121(10), 2814-2832.

Grell, G., 1993: Prognostic evaluation of assumptions used by cumulus parameterizations. Mon. Wea. Rev., 121, 764-787.

Grell, G., J. Dudhia, and D.R. Stauffer, 1993: A description of the fifth generation Penn State/ NCAR mesoscale model (MM5). NCAR Tech. Note., NCARTN-398+IA, Nat. Cent. for Atmos. Res., Boulder, CO, 107pp.

Hong, S.-Y., and H.-L. Pan, 1996: Nonlocal boundary layer vertical diffusion in a medium-range forecast model. Mon. Wea. Rev., 124, 23222339.

Jakob, C., 1999: Cloud cover in the ECMWF reanalyses. J. Climate, 12, 947-959.

Jakob, C., 2003: An improved strategy for the evaluation of cloud parameterizations in GCMs. Bull. Amer. Meteor. Soc., 84(10), 1387-1401.

Kain, J.S., and J.M. Fritsch, 1993: Convective pa- 
rameterization in mesoscale models: The KainFritsch scheme." In The Representation of $\mathrm{Cu}$ mulus Convection in Numerical Models, AMS Monograph, K.A. Emanuel and D.J. Raymond, Eds., 165-170.

Lau, K.-M., G.J. Yang, and S.H. Shen, 1988: Seasonal and intraseasonal climatology of summer monsoon rainfall over East Asia. Mon. Wea. Rev., 116, 18-37.

Leung, L.R., Y. Qian, and X. Bian, 2003a: Hydroclimate of the western United States based on observations and regional climate simulation of 1981-2000. Part I: Seasonal statistics. J. Climate, 16(12), 1892-1911.

and A. Hunt, 2003b: Hydroclimate of the western United States based on observations and regional climate simulation of 1981-2000. Part II: Mesoscale ENSO anomalies. J. Climate, 16(12), 1912-1928.

- S.J. Ghan, Z.-C. Zhao, Y. Luo, W.-C. Wang, and H.-L. Wei, 1999: Intercomparison of regional climate simulations of the 1991 summer monsoon in eastern Asia. J. Geophys. Res., 104, 6425-6454.

, and - 1998: Parameterizing subgrid orographic precipitation and surface cover in climate models. Mon. Wea. Rev., 126(12), 3271-3291.

Mlawer, E.J., S.J. Taubman, P.D. Brown, M.J. Iacono, and S.A. Clough, 1997: Radiative transfer for inhomogeneous atmospheres: RRTM, a validated correlated-k model for the longwave. J. Geophys. Res., 102(D14), 16663-16682.

Rajeevan, M., and J. Srinvivasan, 2000: Net cloud radiative forcing at the top of the atmosphere in the Asian Monsoon region. J. Climate, 13, 650-657.

Reisner, J., R.J. Rasmussen, and R.T. Bruintjes, 1998: Explicit forecasting of supercooled liquid water in winter storms using the MM5 mesoscale model. Quart. J. Roy. Meteor. Soc., 124B, 1071-1107.

Stephens, G.L., S. Ackerman, and E.A. Smith, 1984: A shortwave parameterization revised to improve cloud absorption. J. Atmos. Sci., 41, 687690.

Wang, Y., O.L. Sen, and B. Wang, 2003: A highly resolved regional climate model (IPRC-RegCM) and its simulation of the 1998 severe precipitation event over China. Part I: Model description and verification of simulation. J. Climate, 16, 1721-1738. 